\title{
Rapid establishment of thermophilic anaerobic microbial community during the one-step startup of thermophilic anaerobic digestion from a mesophilic digester
}

\author{
Zhe Tian $^{a}$, Yu Zhang ${ }^{a, *}$, Yuyou Li $^{b}$, Yongzhi Chi ${ }^{a}$, Min Yang ${ }^{a}$ \\ ${ }^{a}$ Key Laboratory of Drinking Water Science and Technology, Research Center for Eco-Environmental Sciences, \\ Chinese Academy of Sciences, P.O. Box 2871, Beijing 100085, China \\ ${ }^{\mathrm{b}}$ Department of Civil and Environmental Engineering, Graduate School of Engineering, Tohoku University, 6-6-06, \\ Aramakiaza-Aoba, Aoba-ku, Sendai, Miyagi 980-8579, Japan
}

\section{A R T I C L E I N F O}

\section{Article history:}

Received 4 August 2014

Received in revised form

25 October 2014

Accepted 2 November 2014

Available online 13 November 2014

Keywords:

One-step startup

Thermophilic anaerobic digestion

Thermophilic anaerobic microbial

community

Establishment

\begin{abstract}
A B S T R A C T
The purpose of this study was to explore how fast the thermophilic anaerobic microbial community could be established during the one-step startup of thermophilic anaerobic digestion from a mesophilic digester. Stable thermophilic anaerobic digestion was achieved within 20 days from a mesophilic digester treating sewage sludge by adopting the one-step startup strategy. The succession of archaeal and bacterial populations over a period of 60 days after the temperature increment was followed by using 454pyrosequencing and quantitative PCR. After the increase of temperature, thermophilic methanogenic community was established within 11 days, which was characterized by the fast colonization of Methanosarcina thermophila and two hydrogenotrophic methanogens (Methanothermobacter spp. and Methanoculleus spp.). At the same time, the bacterial community was dominated by Fervidobacterium, whose relative abundance rapidly increased from 0 to $28.52 \%$ in 18 days, followed by other potential thermophilic genera, such as Clostridium, Coprothermobacter, Anaerobaculum and EM3. The above result demonstrated that the one-step startup strategy could allow the rapid establishment of the thermophilic anaerobic microbial community.
\end{abstract}

๑ 2014 Elsevier Ltd. All rights reserved.

\section{Introduction}

Anaerobic digestion (AD) is a widely applied technology for sewage sludge disposal, which offers the advantage of rapid stabilization of organic matter, reduction in sludge volume, and generation of energy from the produced biogas (Maroun and El Fadel, 2007; Appels et al., 2008). The AD process can be applied at two temperature ranges, namely mesophilic $\left(30-40^{\circ} \mathrm{C}\right)$ and thermophilic $\left(45-60^{\circ} \mathrm{C}\right)$ (Cha and Noike, 1997), because of the presence of two groups of methanogens, and most of the full-scale AD digesters treating sewage sludge have been operated at the mesophilic condition because of the relatively low operation cost (Kardos et al., 2011). Though with a higher operation cost, the thermophilic digestion has also been focused because of the higher specific gas output

* Corresponding author. Tel.: +86 10 62923475; fax: +861062923541. http://dx.doi.org/10.1016/j.watres.2014.11.001

0043-1354/@ 2014 Elsevier Ltd. All rights reserved. 
(Mladenovska and Ahring, 2000; Zabranska et al., 2002). Another merit of the thermophilic digestion is the higher pathogen reduction rates (Watanabe et al., 1997), which is important for the use or disposal of sewage sludge (US. EPA, 1993). Recent studies have shown that thermophilic digestion is more efficient in reducing antibiotic resistance genes than mesophilic digestion (Ghosh et al., 2009; Diehl and LaPara, 2010; Ma et al., 2011). Due to the lack of bulk thermophilic inocula, however, it is necessary to transform mesophilic sludge to thermophilic for the startup of full-scale thermophilic digesters. The transformation of seed sludge has been considered a time-consuming process, usually taking two months, or even longer (Kugelman and Guida, 1989; de la Rubia et al., 2005).

Until now, two startup strategies have been adopted for the transformation of mesophilic sludge to thermophilic: onestep or step-wise temperature increase (Iranpour et al., 2002; Boušková et al., 2005). In general, anaerobic digestion involves numerous interactions among the four major groups of microbes, i.e., hydrolytic-fermentative bacteria, acetogenic bacteria, aceticlastic methanogens and hydrogenotrophic methanogens (Griffin et al., 1998). In a stable anaerobic digestion system, balanced carbohydrate fermentation proceeds by these microorganisms with methane and carbon dioxide as the main products (Sofer and Zaborsky, 1981). Among the four microbial groups, the methanogens are considered to be the most sensitive to temperature changes and the key to the stability of anaerobic digestion systems (Vanlier et al., 1993). It has been assumed that abrupt elevation of temperature may destroy the original metabolic community for methane production in mesophilic sludge, resulting in serious accumulation of hydrogen and volatile fatty acids (VFA) produced during fermentation and acetogenesis (Griffin et al., 1998), which might cause digester upset. Therefore, the step-wise approach has been frequently applied based on the assumption that gradual increase of temperature could be helpful in maintaining the stability of methanogenesis during the startup period (Garber, 1982; Rimkus et al., 1982; de la Rubia et al., 2005). However, Boušková et al. (2005) found that, in comparison with the step-wise temperature increase strategy, the one-step strategy could significantly reduce the transition time.

The key to successfully transform mesophilic digestion to thermophilic operation is the establishment of a thermophilic metabolic community for methane production. Although in low abundance, thermophiles, which are responsible for methane production in thermophilic conditions, were found to be present in mesophilic sludge (Chen, 1983). So, the onestep increase of temperature to the optimum conditions for thermophiles will provide an advantage for their rapid colonization of a reactor, which was assumed to be the main reason for the reduction in transition time (Boušková et al., 2005). However, direct evidence for the above hypothesis is limited and it is still not clear how fast a stable thermophilic metabolic community could be established in an anaerobic digestion system using the one-step strategy.

Therefore, the aim of this study was to investigate the adaptation processes of the bacterial and archaeal populations during the transition of anaerobic digestion from mesophilic $\left(35^{\circ} \mathrm{C}\right)$ to thermophilic conditions $\left(55^{\circ} \mathrm{C}\right)$ using the one-step strategy. The performance of a completely stirred tank reactor (CSTR) was continuously monitored over a period of 80 days after the hike of temperature to $55{ }^{\circ} \mathrm{C}$, and the changes of bacterial and archaeal populations were followed by 454-pyrosequencing and quantitative PCR (qPCR). The result of this study will be helpful in achieving quick startup of thermophilic AD systems.

\section{Material and methods}

\subsection{Reactor system, startup and operation of anaerobic digester}

The experiment was carried out in one CSTR reactor of $6 \mathrm{~L}$ working volume. The reactor system consists of a feed tank $\left(4{ }^{\circ} \mathrm{C}\right)$, feed pump, reactor, effluent pump, effluent bottle and wet gas meter. The temperature was controlled by circulating hot water in the water jacket of the reactor. The reactor was initially inoculated with mesophilic digested sludge $\left(35^{\circ} \mathrm{C}\right)$ from Gaobeidian WWTP, from which sewage sludge, a mixture of primary sludge and secondary sludge fed to the reactor, was also collected. The characteristics of the substrate are listed in Table S1.

The CSTR was operated at constant feed rate of $300 \mathrm{~mL} /$ day and solid retention time (SRT) of 20 days, which is often used for anaerobic mesophilic digestion studies (Griffin et al., 1998; Bolzonella et al., 2005; Boušková et al., 2005). Substrate was fed into the reactor once a day. The reactor was maintained at mesophilic condition $\left(35^{\circ} \mathrm{C}\right)$ for more than 100 days and was at steady state before the experiment started. Characteristics obtained from the steady state mesophilic operation were used as initial values. On day 1 , the temperature of the reactor was directly increased to $55^{\circ} \mathrm{C}$, but each day after that, $300 \mathrm{~mL}$ of digester content was still removed from the reactor and $300 \mathrm{~mL}$ of the substrate was still added to keep a constant SRT. Meanwhile, $\mathrm{NaHCO}_{3}$ was added to the feed during the first SRT (from day 1 to day 20) after temperature elevation to prevent any $\mathrm{pH}$ drop that might lead to digester failure. Biogas production, VFA content and $\mathrm{pH}$ of the digested sludge were chosen as the main parameters to monitor the process stability.

\subsection{Chemical analyses}

Biogas production and $\mathrm{pH}$ were measured daily. The individual VFA concentrations, dissolved chemical oxygen demand (dCOD), $\mathrm{NH}_{4}^{+}-\mathrm{N}$ and alkalinity were measured daily for the first week and 2-3 times per week thereafter. Solids were measured 1-2 times per week. A portion of the $300-\mathrm{mL}$ digested sludge sample was centrifuged at $10,000 \mathrm{rpm}$ for $10 \mathrm{~min}$ and the resulting supernatant passed through a $0.22 \mu \mathrm{m}$ filter before dCOD, $\mathrm{NH}_{4}^{+}-\mathrm{N}$ and alkalinity analyses. dCOD and $\mathrm{NH}_{4}^{+}-\mathrm{N}$ were measured by a spectrophotometric method (Shimadzu UV-160) (Wei, 2002). Bicarbonate and total alkalinity were determined by titrating to $\mathrm{pH} 5.8$ and 4.3, respectively (Greenberg et al., 1992). For VFA, the samples were acidified with $6 \mathrm{M} \mathrm{HCl}$ to lower the $\mathrm{pH}$ below 3, and centrifuged at 10,000 rpm for $10 \mathrm{~min}$. The supernatant was filtered with a $0.22 \mu \mathrm{m}$ membrane and 1-butanol was added as 
the internal standard, then it was transferred to glass GC vials. Individual VFA (acetate, propionate, butyrate, isobutyrate, valerate, and isovalerate) concentrations were determined by a gas chromatograph (Shimazu GC2010-plus) equipped with a flame ionization detector and Stabilwax-DA column (30 $\mathrm{m} \times 0.53 \mathrm{~mm} \times 0.1 \mu \mathrm{m})$. Temperature program used: $70{ }^{\circ} \mathrm{C}$ (1 $\mathrm{min}), 20^{\circ} \mathrm{C} / \mathrm{min}$. to $150^{\circ} \mathrm{C}(0 \mathrm{~min}), 4^{\circ} \mathrm{C} / \mathrm{min}$. to $160^{\circ} \mathrm{C}(0 \mathrm{~min})$, and $20^{\circ} \mathrm{C} / \mathrm{min}$. to $210^{\circ} \mathrm{C}(2 \mathrm{~min})$. The injector temperature was $240^{\circ} \mathrm{C}$ and the detector temperature was $260^{\circ} \mathrm{C}$. Helium was the carrier gas with an initial pressure of $16.3 \mathrm{kPa}$. Methane content in the biogas was only analyzed when the reactor was in steady-state mesophilic or thermophilic condition using a gas chromatograph (Shimazu GC-2010 plus) equipped with a thermal conductivity detector. Total solids and volatile solids were measured according to Niu et al. (2013).

\subsection{DNA extraction}

Together with the sewage sludge (SS), sludge samples of Day $0,4,11,18,26,34,44$, and 57 (as indicated by the arrows in Fig. 1) were taken from the reactor for microbial analysis. One milliliter of each sludge sample was centrifuged at 10,000 rpm for $10 \mathrm{~min}$ at $4{ }^{\circ} \mathrm{C}$, and the resulting sediment was used for DNA extraction using FastDNA ${ }^{\circledR}$ SPIN kit for soil (Qbiogene, Solon $\mathrm{OH}$ ) according to manufacturer's instructions. For each sample, DNA was extracted in duplicate to avoid bias, and the extracts from the same sample were pooled. Concentration and quality of the extracted DNA were checked by spectrophotometric analysis on a NanoDrop ND-1000 (Nanodrop, USA) and electrophoresis on a 1\% (weight/volume) agarose gel.

\subsection{High-throughput 454 pyrosequencing}

For 454-pyrosequencing, 16S rRNA genes were amplified with the primers 27F (5'-AGAGTTTGATCCTGGCTCAG-3') and 534R (5'-TTACCGCGGCTGCTGGCAC-3') (Delong, 1992; Koike et al., 2007) for bacteria and Arch344F (5'-ACGGGGYGCAGCAGGCGCGA-3') and Arch915R (5'GTGCTCCCCCGCCAATTCCT-3') (Weiss et al., 2008) for archaea. Barcodes that allow sample multiplexing during pyrosequencing were incorporated between the 454 adapter and the forward primers (Wu et al., 2012). The length of the amplicon, including the barcode and 454 primers, was 596 nt. PCR mixtures $(50 \mu \mathrm{L})$ were prepared in triplicate and each contained $0.6 \mu \mathrm{M}$ each of the primers, $\sim 5 \mathrm{ng}$ of template DNA, $1 \times$ PCR reaction buffer, and $2.5 \mathrm{U}$ of Pfu DNA Polymerase. The PCR reactions were performed with the following program: $94{ }^{\circ} \mathrm{C}$ for $4 \mathrm{~min} ; 25$ cycles at $94^{\circ} \mathrm{C}$ for $30 \mathrm{~s}, 55^{\circ} \mathrm{C}$ for $30 \mathrm{~s}, 72^{\circ} \mathrm{C}$ for $30 \mathrm{~s}$, and then $72{ }^{\circ} \mathrm{C}$ for $10 \mathrm{~min}$. Triplicate PCR products of the same sample were assembled within a PCR tube. The PCR products of bacteria and archaea were purified and then sequenced by the pyrosequencing method on a 454 Life Sciences Genome SequencerFLX (Roche Diagnostics, Indianapolis, IN, USA) machine. Raw pyrosequencing data that obtained from this study were deposited to the NCBI Sequence Read Archive (SRA, http:// trace.ncbi.nlm.nih.gov/Traces/sra/sra.cgi?) with accession no. SRP049225 (Bacteria) and no. SRP049228 (Archaea).

After sequencing was completed, the sequence reads were analyzed using the Mothur software (Schloss et al., 2009), which is widely used for microbial ecology studies. Briefly, raw sequence reads were first filtered to remove the sequences with quality scores below 25 . The multiplexed reads were then assigned to samples based on their nucleotide barcodes. Thereafter, sequence reads that did not perfectly match the proximal PCR primer, were less than $200 \mathrm{bp}$ for bacteria and archaea, had homopolymers longer than six nucleotides, contained one or more ambiguous base(s), or flagged as chimeric artifacts checked by UCHIME (http://drive5.com/ uchime) were removed. The rest of the sequences were trimmed and aligned against the silva database (version: SSU111 http://www.arb-silva.de/) using k-mer searching (http://www.mothur.org/wiki/Align.seqs). Then, the sequences were clustered into operational taxonomic units (OTUs, 97\% similarity) using Furthest neighbor method (http:// www.mothur.org/wiki/Cluster). Taxonomic classification down to the phylum, class, order, family, and genus level was performed using Mothur (http://www.mothur.org/wiki/ Classify.seqs) via the aforementioned silva database and the algorithm of Naïve Bayesian Classifier (Wang et al., 2007) with a confidence threshold of $80 \%$ (Ma et al., 2013). Rarefaction curves and the Shannon index (http://www.mothur.org/wiki/ Shannon) were also generated in Mothur for each sample. Hierarchical cluster analysis was performed using R 3.0.3 (http://www.r-project.org/) with the gplots package (http:// cran.r-project.org/src/contrib/gplots_2.14.2.tar.gz).

\subsection{Quantitative PCR assay}

The 16S rRNA genes for domain Archaea and Bacteria were quantified respectively for the nine samples using SYBRGreen real-time qPCR. The qPCR analysis was conducted as described previously (Liu et al., 2012). Simply, standard plasmids carrying target genes were obtained by TA clones and extracted using a TIANpure Mini Plasmid kit (Tiangen, China). Concentrations of the standard plasmids $\left(\mathrm{ng} \cdot \mu \mathrm{L}^{-1}\right)$ were determined with Nanodrop, and their copy concentrations (copies $\cdot \mu \mathrm{L}^{-1}$ ) were then calculated (Pei et al., 2006). A $25 \mu \mathrm{L}$ reaction system was used typically containing $1 \times$ Sybr Green I, $1 \times$ Dye (Takara), $200 \mathrm{nM}$ each primer, $0.5 \mathrm{mg} \mathrm{mL}^{-1} \mathrm{BSA}$, and $2 \mu \mathrm{L}$ DNA templates, and qPCR was run on an ABI7300 apparatus (ABI, USA). The specificity was assured by the melting curves and gel electrophoresis. Triplicate qPCR assays were performed for the decimally diluted standard plasmids to obtain the standard curves, by which the quantity of target DNA in samples was calculated. The detailed temperature program of QPCR and criterions for quality control of the quantitative results were discussed in detail in our previous work (Liu et al., 2012), and primers targeting both genes and their amplification sizes and conditions are listed in Table S2. Quality control of the qPCR methods for both 16s rDNA genes are shown in Table S3.

\subsection{Deduction of the doubling time of genus Methanosarcina}

The doubling time of the genus Methanosarcina in the first 11 days after the temperature increase was roughly deduced based on Formula (1) and (2). 

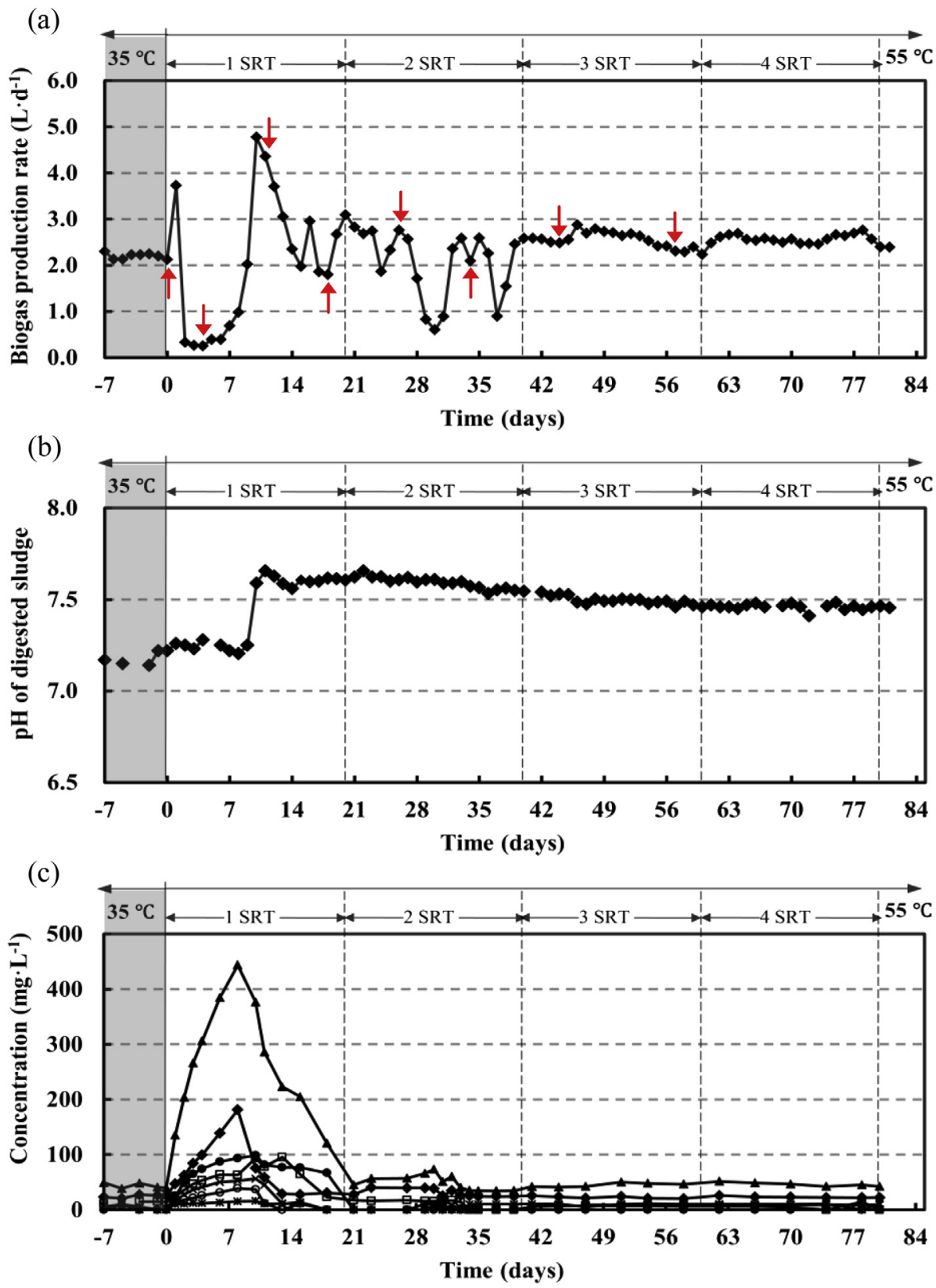

Fig. 1 - Process performances of the CSTR reactor during the one-step increase of the operational temperature: (a) Biogas production $\left(\mathrm{L} \cdot \mathrm{d}^{-1}\right)^{\mathrm{a}}$; (b) $\mathrm{pH}$ of the digested sludge; (c) individual VFA concentration in digested sludge $\left(\mathbf{m g} \cdot \mathrm{L}^{-1}\right):-\mathrm{acetate}^{-}$ $\square$-propionate; $\bigcirc$-butyrate; $\times$-isobutyrate; *-valerate; $\bullet$-isovalerate; $\Delta-$ Total VFAs ${ }^{\mathrm{b}}$. ${ }^{\mathrm{a}}$ Arrows in Fig. $1 \mathrm{a}$ indicate the dates that sludge samples were taken for microbial analysis. ${ }^{b}$ Total VFAs equals the sum of the concentrations of acetate, propionate, butyrate, valerate, isovalerate, and isobutyrate as measured by gas chromatography. (For interpretation of the references to colour in this figure legend, the reader is referred to the web version of this article.)

$f(t+1)=\frac{(5.7 \times f(t)+0.3 \times \alpha)}{6} \times 2^{1 / D}$

Leastsquares $\left(\times 10^{-16}\right)=\frac{\left(f(4)-1.52 \times 10^{5}\right)^{2}+\left(f(11)-7.91 \times 10^{8}\right)^{2}}{10^{16}}$

$f(t)$ was the calculated quantity (copies $\mathrm{mL}^{-1}$ ) of the genus Methanosarcina in digested sludge on day $t$. Because the measured relative abundance of Methanosarcina in mesophilic sludge (Day 0) was $0 \%$, which might due to the bias of PCR amplification before pyrosequencing, $f(0)$ equaled 0 after being multiplied by the total amount of archaea in mesophilic sludge. $\alpha$ was the mean concentration $\left(3.65 \times 10^{4}\right.$ copies $\left.\cdot \mathrm{mL}^{-1}\right)$ of the genus in sewage sludge. $D$ was the deduced doubling time in unit of days. The values of $1.52 \times 10^{5}$ and $7.91 \times 10^{8}$ in Equation (2) were the measured mean concentrations of Methanosarcina in sludge samples of day 4 and 11, respectively. Least squares was the minimum sum of the squares of the errors between the calculated quantities and the measured quantities of Methanosarcina in sludge of day 4 and 11, which was used to judge the best deduced value of $D$. Considering the plentiful VFAs (especially acetate) present in sludge in the first 
11 days, Formula (1) was a simulation of the logarithmic growth of this genus and the value of $D$ that generated the minimum value of the least squares in Formula (2) was considered the doubling time.

\section{Results}

\subsection{Performance of the CSTR reactor}

The operation temperature of the CSTR reactor was increased from $35^{\circ} \mathrm{C}$ to $55^{\circ} \mathrm{C}$ in one step, and its performance is revealed as shown in Fig. 1. Following the sudden increase of the biogas production on day 1 , the biogas production dropped to its minimum value of around $0.3 \mathrm{~L} \cdot \mathrm{d}^{-1}$ on day 2 and began to increase from day 7 , reaching the peak value of $4.8 \mathrm{~L} \cdot \mathrm{d}^{-1}$ on day 10. After a period of fluctuation, the biogas production finally stabilized from day 40 on with a value of approximately $2.5 \mathrm{~L} \cdot \mathrm{d}^{-1}$ (Fig. 1a). The methane content of biogas under the thermophilic steady-state was $74 \%$, which was higher than that (62\%) under mesophilic conditions. All of the VFAs began to accumulate immediately following the increase of temperature (Fig. 1c). However, the maximum concentrations of acetate and propionate were approximately 180 and $100 \mathrm{mg} \cdot \mathrm{L}^{-1}$, respectively, which did not reach levels affecting system stability (Kroeker et al., 1979; Kalle and Menon, 1984). The concentrations of VFAs began to decrease from day 7 , which was in accordance with the change of biogas production, suggesting that the thermophiles began to function in the system. Despite the accumulation of VFAs, the $\mathrm{pH}$ of the digested sludge exhibited a sudden increase from 7.2 to 7.6 on day 10 , together with the increase of biogas production, and remained around this value for the rest of the experiment (Fig. 1b). The changes in dissolved $\mathrm{COD}, \mathrm{NH}_{4}^{+}-\mathrm{N}$, alkalinity, total solids (TS) and volatile solids (VS) of the digested sludge are displayed in Fig. S1-S3 in supplementary material. All of the performance data suggested that significant thermophilic methanogenesis occurred from day 7 on and the thermophilic anaerobic digester could be rapidly started up from a steadystate mesophilic system with the one-step temperature increase strategy.

\subsection{Changes of archaeal population}

In general, the archaeal population was relatively simple (Fig. S4): only 35 OTUs were generated by setting $97 \%$ sequence similarity, and most of them were assigned to methanogenic archaea. Hierarchical cluster analysis showed that significant changes in the methanogenic community occurred on day 11 (Fig. 2a). Mesophilic sludge was dominated by the aceticlastic Methanosaeta (79.94\%) followed by the hydrogenotrophic Methanolinea (16.61\%) (Fig. 2b). Starting on day 11, members of Methanosarcina, another aceticlastic methanogen, became the most dominant (>73\%) throughout the whole experimental period, while Methanosaeta declined to a negligible level (3.19\%). Meanwhile, Methanothermobacter and Methanoculleus became the most abundant hydrogenotrophic methanogens. The level of Methanolinea in digested sludge decreased from $16.61 \%$ on day 0 to $3.23 \%$ on day 11 and less than $0.2 \%$ on day 57. After the sharp increase on day 11 , the abundance of
Methanothermobacter gradually decreased during the remaining experiment (from $3.79 \%$ to $0.93 \%$ ), in comparison with the increase of the Methanoculleus's level (from $2.42 \%$ to $10.39 \%$ ) suggesting that there existed a competitive growth between these two hydrogenotrophic methanogens. Methanospirillum, Mthanosphaerula, Methanobrevibacter and Methanobacterium were also present in the digester, but their relative abundances remained low $(<1 \%)$ throughout the experiment.

At the same time, the total archaeal concentration was also followed using qPCR, as shown in Fig. S6. The total archaeal concentration decreased over the initial four days, suggesting that the growth of thermophilic methanogens was quite slow, and was not able to compensate the loss of mesophilic methanogens through wash-out during the period. Then, the total archaeal concentration significantly increased and reached a comparable level $\left(1.08 \times 10^{9}\right.$ copies $\left.\cdot \mathrm{mL}^{-1}\right)$ on day 11 with that $\left(9.85 \times 10^{8}\right.$ copies $\left.\cdot \mathrm{mL}^{-1}\right)$ before the hike of temperature. Thereafter, the total amount of archaea gradually increased until day 26 , and finally stabilized at a lower level $\left(5.00 \times 10^{8}\right.$ copies $\left.\cdot \mathrm{mL}^{-1}\right)$ (Fig. S6).

\subsection{Changes of bacterial population}

After the filtering process, finally 112,849 high-quality bacterial reads (average length of $472.7 \mathrm{bp}$ ) were generated from the PCR amplicons, with which a total of 1550 OTUs were clustered based on $97 \%$ identity. Rarefaction curves of any of the nine bacterial 16S rRNA gene libraries from pyrosequencing did not reach saturation even after 10,000 reads sampling (Fig. S5), suggesting the high bacterial richness in anaerobic sludge. Mesophilic sludge (day 0) exhibited a large bacterial diversity, with the Shannon diversity index at 5.15. After the temperature increase, the Shannon diversity index of anaerobic sludge slightly increased during the first four days, then gradually decreased and dropped to its minimum value of 4.27 on day 26 , and finally stabilized around at 4.50 in thermophilic sludge (Fig. S9), which was lower than that of mesophilic sludge. Previous studies have also shown that the thermophilic systems have a lower bacterial diversity than mesophilic ones (Shigematsu et al., 2006; Liu et al., 2009).

A total of 374 genera affiliated to 36 phyla were identified using the Bayesian method. Hierarchical cluster analysis using all the OTUs based on the genus level showed the bacterial communities could also be divided into two groups: one group for samples of day 0 and day 4, and another group for the rest (Fig. 3a). The bacterial community was dominant, with the phyla Proteobacteria (23.29\%), Bacteroidetes (19.08\%), Firmicutes (15.45\%), Chloroflexi (12.70\%) and Actinobacteria $(12.60 \%)$ in mesophilic sludge (day 0), while the dominant phyla on day 44 were Firmicutes (36.77\%), Thermotogae (21.36\%), Actinobacteria (14.27\%), Proteobacteria (12.35\%) and Synergistetes (5.70\%). In comparison with mesophilic sludge, the relative abundances of the phyla Bacteroidetes, Chloroflexi and Proteobacteria decreased, while those of the phyla Firmicutes, Synergistetes and Thermotogae increased.

To further infer the functional adaption of the bacterial community, we ranked the identified OTUs at the genus level, and twenty bacterial genera whose relative abundances significantly changed during the transition period were picked out (Fig. 3c and d and Table S4). Bacteroides (10.57\%), Longilinea 
(a)

Archaea

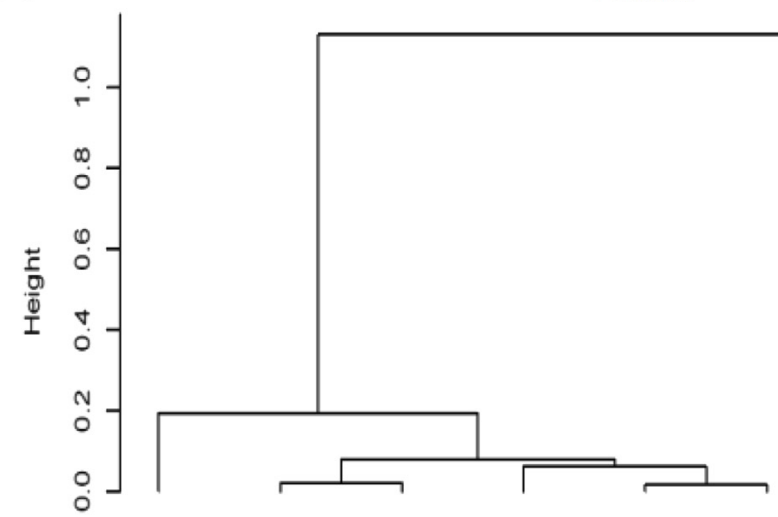

(b)

Day 11 Day 44 Day 57 Day 18 Day 26 Day 34 SS Day 0 Day 4

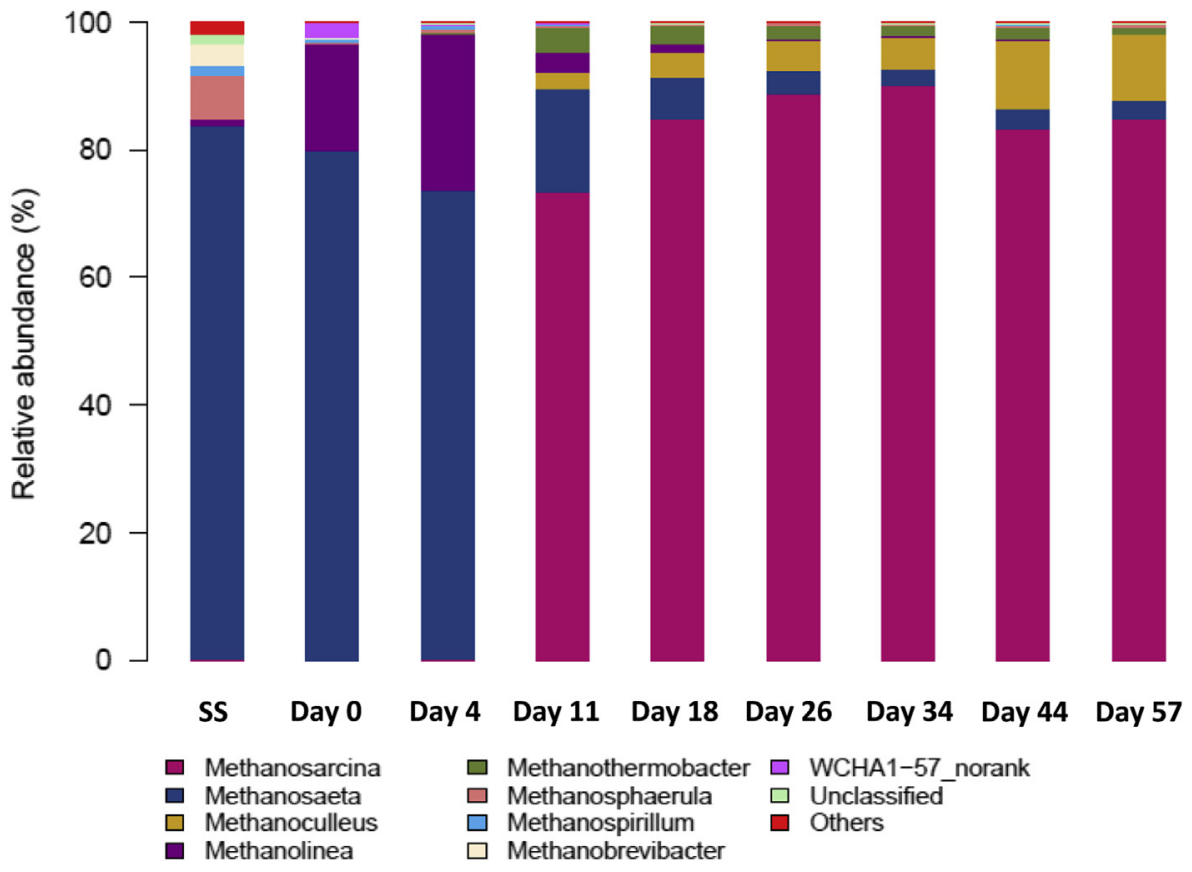

Fig. 2 - Succession of archaeal population: (a) Hierarchical cluster analysis of nine archaeal communities. The analysis is the clustering of all OTUs ( $3 \%$ distance), which were ordered by genus. Sample communities were clustered based on average linkage method. (b) Archaeal community structures at genus level in the CSTR reactor monitored using pyrosequencing. Relative abundance was defined as the number of sequences affiliated with that genus divided by the total number of sequences per sample.

(1.67\%), Exilispira (1.60\%), Leeia (1.35\%), Leptolinea (1.33\%) and Paludibacter $(0.94 \%)$ were the dominant fermentative acidogenic bacteria in mesophilic sludge. At the same time, Smithella $(7.79 \%)$, Syntrophobacter $(0.24 \%)$, Syntrophus $(1.61 \%)$ and Syntrophomonas (0.49\%) were dominant mesophilic syntrophic fatty-acid-oxidizing bacteria, which could convert various organic acids produced in hydrolysis and acidogenesis steps to hydrogen and acetate for subsequent methanogenesis. After the temperature increase, the relative abundances of the above genera except Longilinea markedly declined over the first 11 days, while the relative abundance of Longilinea first increased to $4.85 \%$ on day 11 , then gradually declined to less than $1 \%$ on day 57 (Fig. 3d). On the other hand, anaerobic species from genera of 060F05-B-SD-P93, Sarcina, Clostridium,
Anaerobaculum, Coprothermobacter, Fervidobacterium and EM3 represented the major fermentative acidogenic bacteria in thermophilic sludge (Fig. 3c). Fervidobacterium showed a fast proliferation in the first 18 days. With a significant drop on day 26 , its relative abundance quickly rebounded to a high level (27.55\%) on day 34 , then gradually decreased to about $10 \%$ on day 57. On the contrary, the other six acidogenic bacterial genera became abundant mainly from day 26 , suggesting that Fervidobacterium might have played an important role in the processes of fermentation and acidogenesis during the initial stage (day $0-18$ ) of the transition period. The relative abundance of Petrobacter, a thermophilic genus that could metabolize various organic acids and ethanol in the presence of nitrate as the terminal electron acceptor (Salinas et al., 2004) 
(a)

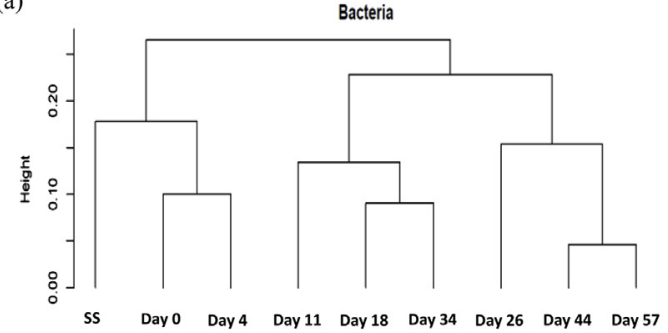

(b)

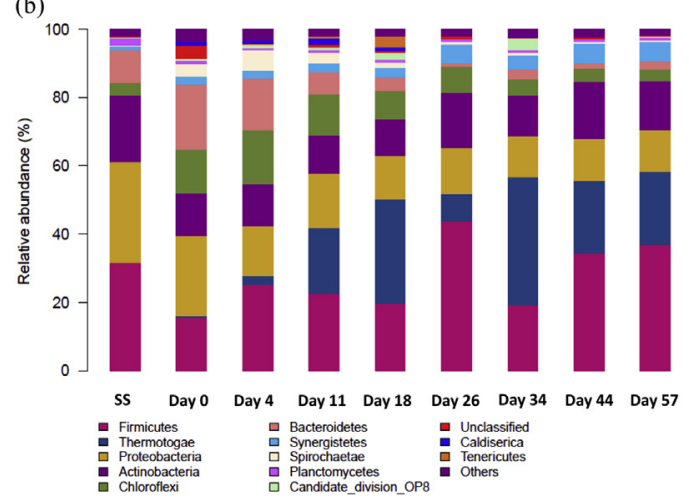

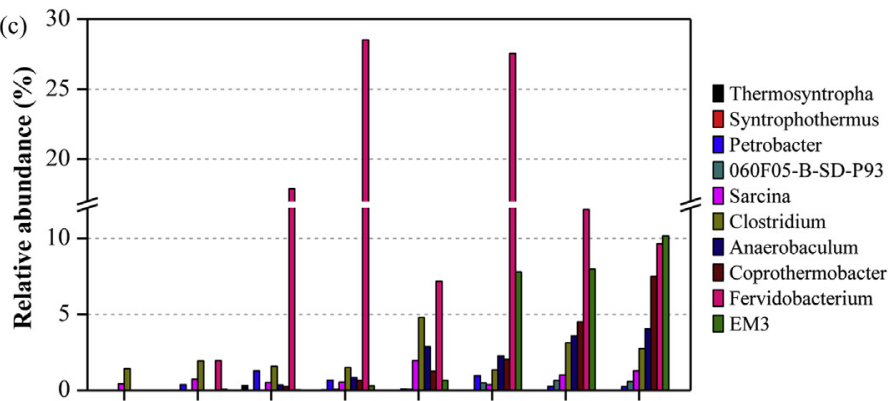

(d)

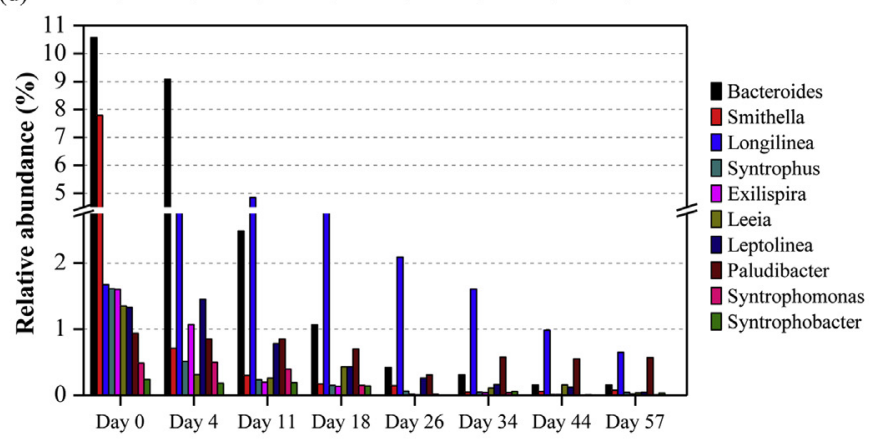

Fig. 3 - Succession of bacterial population: (a) Hierarchical cluster analysis of nine bacterial communities. The analysis is the clustering of all OTUs (3\% distance), which were ordered by genus. Sample communities were clustered based on average linkage method. (b) Bacterial community structures at phylum level in the CSTR reactor monitored using pyrosequencing. Relative abundance was defined as the number of sequences affiliated with that phylum divided by the total number of sequences per sample. (c) Ten bacterial genera whose abundances increased during the experiment. (d) Ten bacterial genera whose abundances decreased during the experiment.

first increased to a level of $1.29 \%$ on day 11 , and subsequently decreased to $0.24 \%$ on day 57 , which was still higher than the level $(0.008 \%)$ in mesophilic sludge. Thermosyntropha and Syntrophothermus, the two thermophilic fatty-acid-oxidizing bacteria genera (Shigematsu et al., 2006), were also detected in thermophilic sludge. The genus Thermosyntropha emerged on day $4(0.024 \%)$ immediately after the temperature change and rapidly proliferated to the level of $0.31 \%$ on day 11 , but no related OTUs were found from day 26 on. Another syntrophic bacterial genus Syntrophothermus was first detected on day 18 with a relative abundance of $0.031 \%$, and remained at a low level for the rest of the experiment.

The total bacterial concentration in anaerobic sludge quantified by qPCR showed a similar fluctuation pattern to that of archaea, except that the bacterial concentration did not significantly increased from day 4-11. In comparison with mesophilic sludge $\left(6.90 \times 10^{10}\right.$ copies $\left.\cdot \mathrm{mL}^{-1}\right)$, the total amount of bacteria $\left(4.58 \times 10^{10}\right.$ copies $\left.\cdot \mathrm{mL}^{-1}\right)$ in steady-state thermophilic sludge was also slightly low (Fig. S7).

\section{Discussion}

From the engineering application viewpoint, rapid start-up of thermophilic digester is very important. The time required for the successful start-up of thermophilic digester from a steadystate mesophilic system using the strategy of step-wise temperature increase has been reported to be 50-70 days
(Kugelman and Guida, 1989; Boušková et al., 2005). By adopting the one-step temperature increase strategy, the required time for start-up could be shortened to approximately 20 days, as indicated by the high gas production and low VFAs concentrations achieved. As a matter of fact, significant biogas production occurred on day 7 after the elevation of temperature (Fig. 1a), suggesting that the thermophilic methanogenic pathway could be established even with shorter time.

The rapid start-up of thermophilic digestion was achieved because of the rapid establishment of the thermophilic anaerobic microbial community. As for the archaeal population, hierarchical cluster analysis clearly showed that the thermophilic methanogenic community was already established at least on day 11 after the temperature increase (Fig. 2a). Methanosaeta with a low growth threshold for acetate (Zinder et al., 1984) were the most abundant methanogens in mesophilic sludge. After the temperature increase, the dominant position was soon taken over by the genus Methanosarcina (Fig. 2b). To our knowledge, Methanosarcina thermophila is the only thermophilic species in this genus. Methanosarcina strain TM-1, the only type strain of M. thermophila originally isolated from a laboratory-scale $55^{\circ} \mathrm{C}$ anaerobic sludge digester (Zinder and Mah, 1979), was successfully detected in sludge samples by pyrosequencing at species level. So, it is assumed that the Methanosarcina related OTUs detected in this study should belong to M. thermophila. Based on the above assumption, we roughly assessed the proliferation rate of $M$. thermophila in the first 11 days and deduced its 
doubling time using the measured quantities of total archaea by QPCR and the relative abundance of genus Methanosarcina by pyrosequencing, with Formula (1) and (2). The best fit doubling time was 0.58 day (Fig. S8), which was slightly longer than the value of 0.5 day for Methanosarcina thermophila TM-1 under its best growth conditions $\left(50{ }^{\circ} \mathrm{C}\right.$ and acetate as the methanogenesis substrate) (Zinder and Mah, 1979). The above difference was acceptable considering the different temperature and the complex substrates present in anaerobic sludge, which might adversely affect the growth of $\mathrm{M}$. thermophila. Therefore, the immediate logarithmic growth of Methanosarcina thermophila guaranteed the fast establishment of the thermophilic methanogenic community in this study. Similarly, the dominant hydrogenotrophic methanogens also quickly changed from Methanolinea in mesophilic sludge to the genera Methanoculleus and Methanothermobacter after the temperature increase. Considering that both new hydrogenotrophic methanogens are usually found in thermophilic anaerobic digesters (Hori et al., 2006; Yabu et al., 2011) while Methanolinea usually predominates in mesophilic (Bandara et al., 2012) and even low temperature $\left(\leq 20{ }^{\circ} \mathrm{C}\right)$ systems (Sumino et al., 2012; Zhang et al., 2012), temperature should play an important role in the shift of the predominance of the hydrogenotrophic methanogens. It is known that the accumulation of hydrogen usually occurs together with that of VFAs (Bjornsson et al., 2001), so the concentrations of VFAs and hydrogen may have also affected the change of the hydrogenotrophic methanogens. This could explain the observed competitive growth between Methanothermobacter spp., which favors the propionate rich condition, and Methanoculleus spp., which is known to prefer low hydrogen concentrations (Hori et al., 2006).

As for bacterial population, 454-pyrosequencing and cluster analysis revealed that significant changes also occurred on day 11 (Fig. 3). Members of the genus Bacteroides were the predominant hydrolytic-fermentative bacteria in mesophilic sludge, which was consistent with the well-established hydrolytic capacities of species of this group (Sofer and Zaborsky, 1981). The detected syntrophic propionate $\left(C_{3}\right)$ oxidizing bacteria (Smithella and Syntrophobacter) (Liu et al., 1999) and syntrophic long-chain fatty acid (usually $C_{4} \sim C_{18}$ ) -oxidizing bacteria (Syntrophomonas and Syntrophus) (McInerney et al., 1979; Jackson et al., 1999) could carry out organic acid degradation via the $\beta$-oxidation mechanism and lead to the production of acetate and methane through cooperation with hydrogen-utilizing microorganisms (Schink, 1997), such as Methanolinea that was also abundant in the mesophilic sludge. The abundances of the four syntrophs and Bacteroides, which are all mesophilic bacteria with optimal growth temperature around $35^{\circ} \mathrm{C}$, rapidly declined after the temperature increase. Fervidobacterium represented the predominant fermenter in the initial stage of the transition period (day 0-18), and this genus consists of a group of thermophilic bacteria having a wide range of substrates and fast growth rates, with a generation time usually less than $2 \mathrm{~h}$ (Patel et al., 1985; Huber et al., 1990; Friedrich and Antranikian, 1996; Cai et al., 2007), which might explain their quick proliferation immediately after the temperature increase. Perceptible increases in bacterial abundances of other potential thermophilic genera, such as Clostridium, Coprothermobacter and Anaerobaculum belonging to phylum Firmicutes and EM3 belonging to phylum Thermotogae (Reysenbach et al., 1994; Hugenholtz et al., 1998) were not observed until day 26. So it is assumed that the establishment of a stable thermophilic bacterial community was quite slow in comparison with the methanogenic archaeal one.

Most of the thermophilic systems have been started up by employing the step-wise temperature increase strategy, because of the concerns over the sensitivity of methanogens to the variations of temperature (Garber, 1982; Rimkus et al., 1982; de la Rubia et al., 2005). However, the result of this study showed that the thermophilic digestion could be established quickly. The successful start-up of the thermophilic digestion relies on the colonization of sufficient number of thermophiles that are responsible for the production of methane under thermophilic conditions. With the strategy of one-step temperature increase, the thermophiles could grow under their favorite temperature from the beginning. On the contrary, during the step-wise temperature increase, the conditions before the final thermophilic stage are not favorable for the thermophiles (Khemkhao et al., 2012), which could prolong the time required for the successful startup of the thermophilic digester.

A significant decrease in gas production occurred over a period from day 26 to day 31 after the startup of the thermophlic digester (Fig. 1a). However, no obvious fluctuations of $\mathrm{pH}$ and VFA concentrations were observed during this period (Figs. $1 \mathrm{~b}$ and c). The fall of the gas production, which was not observed in previous works (Griffin et al., 1998; Boušková et al., 2005), might be related to the change of the diversity of bacterial population in anaerobic sludge (Fig. S9). With the fast establishment of dominance by the genus Fervidobacterium in the bacteria population after the increase of temperature, the diversity of the bacterial population declined and reached its minimum level on day 26 (Fig. S9). It could be possible that the sole dominance of Fervidobacterium in the bacterial population could not sustain a balanced metabolism of organic substrates (Briones and Raskin, 2003; Girvan et al., 2005), which caused less degradation of organic components in sewage sludge for subsequent methanogenesis, resulting in less gas production. From day 26 on, together with the rises of other fermenters, the diversity of the bacterial population gradually increased, leading to more parallel hydrolytic-fermentative pathways (Werner et al., 2011). Meanwhile, because the methanogenic pathway had already been established, gas production was quickly restored after the adaption of the bacteria population. So, the increase in the abundances of other thermophilic bacteria, such as Clostridium and Anaerobaculum, may have played a key role in constructing a stable anaerobic digestion system.

It should be noted that the time required for start-up may be affected by many other operational conditions, such as source of seed sludge, properties of feed sludge and SRT. For example, the startup time was 30 days in Boušková's work, which also applied the one-step strategy but encountered severe accumulation of propionate after temperature increase (Boušková et al., 2005). In the present study, the high level (7.79\%) of Smithella, which could convert propionate to acetate effectively (Liu et al., 1999), in mesophilic sludge might contribute to the low accumulation of propionate and faster 
start-up (Griffin et al., 1998). On the other hand, the fermenter Fervidobacterium (0.015\%) and the methanogen Methanosarcina (0.11\%), which are important members in the thermophilic metabolic systems, were detected in sewage sludge (Table S5 and S6), suggesting that the feed sludge could also affect the startup process. In addition, PCR and sequencing biases, and the presence of considerable portions of dead cells (mainly from the feed sludge) in sequenced digested sludge may also partially distort the temporal succession result.

\section{Conclusions}

This study showed that thermophilic anaerobic digester can be rapidly started up from a steady-state mesophilic system by adopting the one-step temperature increase strategy. This temperature increase strategy ensured that the thermophiles could grow under their favorite temperature from the beginning, which was the key factor for the rapid establishment of the thermophilic metabolic community. On the other hand, to achieve successful full-scale application, the effects of other operational parameters, such as SRT, the feed sludge types, etc, on the startup of the thermophilic digester should be explored in the future.

\section{Acknowledgments}

This study was supported by National Natural Scientific Foundation of China (No. 51178449), Funds for the Creative Research Groups of China (No. 51221892) and State Hi-tech Research and Development Project of the Ministry of Science and Technology, Peoples Republic of China (Grand) (2012AA063401). We thank Mr. Li Kuixiao for his kind help in collecting sewage sludge.

\section{Appendix A. Supplementary data}

Supplementary data related to this article can be found at http://dx.doi.org/10.1016/j.watres.2014.11.001.

\section{R E F E R E N C E S}

Appels, L., Baeyens, J., Degreve, J., Dewil, R., 2008. Principles and potential of the anaerobic digestion of waste-activated sludge. Prog. Energy Combust. Sci. 34 (6), 755-781.

Bandara, W.M., Kindaichi, T., Satoh, H., Sasakawa, M., Nakahara, Y., Takahashi, M., Okabe, S., 2012. Anaerobic treatment of municipal wastewater at ambient temperature: analysis of archaeal community structure and recovery of dissolved methane. Water Res. 46 (17), 5756-5764.

Bjornsson, L., Murto, M., Jantsch, T.G., Mattiasson, B., 2001. Evaluation of new methods for the monitoring of alkalinity dissolved hydrogen and the microbial community in anaerobic digestion. Water Res. 35 (12), 2833-2840.

Bolzonella, D., Pavan, P., Battistoni, P., Cecchi, F., 2005. Mesophilic anaerobic digestion of waste activated sludge: influence of the solid retention time in the wastewater treatment process. Process Biochem. 40 (3-4), 1453-1460.

Boušková, A., Dohanyos, M., Schmidt, J.E., Angelidaki, I., 2005. Strategies for changing temperature from mesophilic to thermophilic conditions in anaerobic CSTR reactors treating sewage sludge. Water Res. 39 (8), 1481-1488.

Briones, A., Raskin, L., 2003. Diversity and dynamics of microbial communities in engineered environments and their implications for process stability. Curr. Opin. Biotechnol. 14 (3), 270-276.

Cai, J., Wang, Y., Liu, D., Zeng, Y., Xue, Y., Ma, Y., Feng, Y., 2007. Fervidobacterium changbaicum sp nov., a novel thermophilic anaerobic bacterium isolated from a hot spring of the Changbai Mountains, China. Int. J. Syst. Evol. Microbiol. 57 (Pt 10), 2333-2336.

Cha, G.C., Noike, T., 1997. Effect of rapid temperature change and HRT on anaerobic acidogenesis. Water Sci. Technol. 36 (6-7), 247-253.

Chen, M., 1983. Adaptation of mesophilic anaerobic sewage fermentor populations to thermophilic temperatures. Appl. Environ. Microbiol. 45 (4), 1271-1276.

de la Rubia, M.A., Romero, L.I., Sales, D., Perez, M., 2005. Temperature conversion (mesophilic to thermophilic) of municipal sludge digestion. AIChE J. 51 (9), 2581-2586.

Delong, E.F., 1992. Archaea in coastal marine environments. Proc. Natl. Acad. Sci. U. S. A. 89 (12), 5685-5689.

Diehl, D.L., LaPara, T.M., 2010. Effect of temperature on the fate of genes encoding tetracycline resistance and the integrase of class 1 integrons within anaerobic and aerobic digesters treating municipal wastewater solids. Environ. Sci. Technol. 44 (23), 9128-9133.

Friedrich, A.B., Antranikian, G., 1996. Keratin degradation by Fervidobacterium pennavorans, a novel thermophilic anaerobic species of the order Thermotogales. Appl. Environ. Microbiol. 62 (8), 2875-2882.

Garber, W.F., 1982. Operating experience with thermophilic anaerobic digestion. J. Water Pollut. Control Fed. 54 (8), 1170-1175.

Ghosh, S., Ramsden, S.J., LaPara, T.M., 2009. The role of anaerobic digestion in controlling the release of tetracycline resistance genes and class 1 integrons from municipal wastewater treatment plants. Appl. Microbiol. Biotechnol. 84 (4), 791-796.

Girvan, M.S., Campbell, C.D., Killham, K., Prosser, J.I., Glover, L.A., 2005. Bacterial diversity promotes community stability and functional resilience after perturbation. Environ. Microbiol. 7 (3), 301-313.

Greenberg, A.E., Clesceri, L.S., Eaton, A.D., 1992. Standard Methods for the Examination of Water and Wastewater. American Public Health Association, Washington, D.C.

Griffin, M.E., McMahon, K.D., Mackie, R.I., Raskin, L., 1998. Methanogenic population dynamics during start-up of anaerobic digesters treating municipal solid waste and biosolids. Biotechnol. Bioeng. 57 (3), 342-355.

Hori, T., Haruta, S., Ueno, Y., Ishii, M., Igarashi, Y., 2006. Dynamic transition of a methanogenic population in response to the concentration of volatile fatty acids in a thermophilic anaerobic digester. Appl. Environ. Microbiol. 72 (2), 1623-1630.

Huber, R., Woese, C.R., Langworthy, T.A., Kristjansson, J.K., Stetter, K.O., 1990. Fervidobacterium islandicum sp. nov., a new extremely thermophilie eubacterium belonging to the "Thermotogales". Arch. Microbiol. 154 (2), 105-111.

Hugenholtz, P., Pitulle, C., Hershberger, K.L., Pace, N.R., 1998. Novel division level bacterial diversity in a Yellowstone hot spring. J. Bacteriol. 180 (2), 366-376.

Iranpour, R., Oh, S., Cox, H.H.J., Shao, Y.J., Moghaddam, O., Kearney, R.J., Deshusses, M.A., Stenstrom, M.K., Ahring, B.K., 2002. Changing mesophilic wastewater sludge digestion into 
thermophilic operation at Terminal Island Treatment Plant. Water Environ. Res. 74 (5), 494-507.

Jackson, B.E., Bhupathiraju, V.K., Tanner, R.S., Woese, C.R., McInerney, M.J., 1999. Syntrophus aciditrophicus sp. nov., a new anaerobic bacterium that degrades fatty acids and benzoate in syntrophic association with hydrogen-using microorganisms. Arch. Microbiol. 171 (2), 107-114.

Kalle, G.P., Menon, K.K.G., 1984. Inhibition of methanogenesis and its reversal during biogas formation from cattle manure. J. Biosci. 6 (3), 315-324.

Kardos, L., Juhasz, A., Palko, G., Olah, J., Barkacs, K., Zaray, G., 2011. Comparing of mesophilic and thermophilic anaerobic fermented sewage sludge based on chemical and biochemical tests. Appl. Ecol. Environ. Res. 9, 293-302.

Khemkhao, M., Nuntakumjorn, B., Techkarnjanaruk, S., Phalakornkule, C., 2012. UASB performance and microbial adaptation during a transition from mesophilic to thermophilic treatment of palm oil mill effluent. J. Environ. Manag. 103, 74-82.

Koike, S., Krapac, I.G., Oliver, H.D., Yannarell, A.C., CheeSanford, J.C., Aminov, R.I., Mackie, R.I., 2007. Monitoring and source tracking of tetracycline resistance genes in lagoons and groundwater adjacent to swine production facilities over a 3year period. Appl. Environ. Microbiol. 73 (15), 4813-4823.

Kroeker, E.J., Schulte, D.D., Sparling, A.B., Lapp, H.M., 1979. Anaerobic treatment process stability. J. Water Pollut. Control Fed. 51 (4), 718-727.

Kugelman, I.J., Guida, V.G., 1989. Comparative Evaluation of Mesophilic and Thermophilic Anaerobic Digestion. U.S. Environmental Protection Agency, Risk Reduction Engineering Laboratory, Cincinnati, $\mathrm{OH}$.

Liu, K., Tang, Y.-Q., Matsui, T., Morimura, S., Wu, X.-L., Kida, K., 2009. Thermophilic anaerobic co-digestion of garbage, screened swine and dairy cattle manure. J. Biosci. Bioeng. 107 (1), 54-60.

Liu, M., Zhang, Y., Yang, M., Tian, Z., Ren, L., Zhang, S., 2012. Abundance and distribution of tetracycline resistance genes and mobile elements in an oxytetracycline production wastewater treatment system. Environ. Sci. Technol. 46 (14), 7551-7557.

Liu, Y.T., Balkwill, D.L., Aldrich, H.C., Drake, G.R., Boone, D.R., 1999. Characterization of the anaerobic propioate-degrading syntrophs Smithella propionica gen. nov., sp. nov. and Syntrophobacter wolinii. Int. J. Syst. Bacteriol. 49 (Pt 2), 545-556.

Ma, J., Wang, Z., Yang, Y., Mei, X., Wu, Z., 2013. Correlating microbial community structure and composition with aeration intensity in submerged membrane bioreactors by 454 high-throughput pyrosequencing. Water Res. 47 (2), 859-869.

Ma, Y., Wilson, C.A., Novak, J.T., Riffat, R., Aynur, S., Murthy, S., Prudens, A., 2011. Effect of various sludge digestion conditions on sulfonamide, macrolide, and tetracycline resistance genes and class I integrons. Environ. Sci. Technol. 45 (18), 7855-7861.

Maroun, R., El Fadel, M., 2007. Start-up of anaerobic digestion of source-sorted organic municipal solid waste in the absence of classical inocula. Environ. Sci. Technol. 41 (19), 6808-6814.

McInerney, M.J., Bryant, M.P., Pfennig, N., 1979. Anaerobic bacterium that degrades fatty acids in syntrophic association with methanogens. Arch. Microbiol. 122 (2), 129-135.

Mladenovska, Z., Ahring, B.K., 2000. Growth kinetics of thermophilic Methanosarcina spp. isolated from full-scale biogas plants treating animal manures. FEMS Microbiol. Ecol. 31 (3), 225-229.

Niu, Q., Qiao, W., Qiang, H., Hojo, T., Li, Y.Y., 2013. Mesophilic methane fermentation of chicken manure at a wide range of ammonia concentration: stability, inhibition and recovery. Bioresour. Technol. 137, 358-367.

Patel, B.K.C., Morgan, H.W., Daniel, R.M., 1985. Fervidobacterium nodosum gen. nov. and spec. nov., a new chemoorganotrophic, caldoactive, anaerobic bacterium. Arch. Microbiol. 141 (1), 63-69.
Pei, R., Kim, S.C., Carlson, K.H., Pruden, A., 2006. Effect of river landscape on the sediment concentrations of antibiotics and corresponding antibiotic resistance genes (ARG). Water Res. 40 (12), 2427-2435.

Reysenbach, A.L., Wickham, G.S., Pace, N.R., 1994. Phylogenetic analysis of the hyperthermophilic pink filament community in Octopus Spring, Yellowstone National Park. Appl. Environ. Microbiol. 60 (6), 2113-2119.

Rimkus, R.R., Ryan, J.M., Cook, E.J., 1982. Full-scale thermophilic digestion at the West-Southwest sewage treatment works, Chicago, Illinois. J. Water Pollut. Control Fed. 54 (11), 1447-1457.

Salinas, M.B., Fardeau, M.L., Cayol, J.L., Casalot, L., Patel, B.K.C., Thomas, P., Garcia, J.L., Ollivier, B., 2004. Petrobacter succinatimandens gen. nov., sp nov., a moderately thermophilic, nitrate-reducing bacterium isolated from an Australian oil well. Int. J. Syst. Evol. Microbiol. 54 (Pt 3), 645-649.

Schink, B., 1997. Energetics of syntrophic cooperation in methanogenic degradation. Microbiol. Mol. Biol. Rev. 61 (2), 262-280.

Schloss, P.D., Westcott, S.L., Ryabin, T., Hall, J.R., Hartmann, M., Hollister, E.B., Lesniewski, R.A., Oakley, B.B., Parks, D.H., Robinson, C.J., Sahl, J.W., Stres, B., Thallinger, G.G., Van Horn, D.J., Weber, C.F., 2009. Introducing mothur: opensource, platform-independent, community-supported software for describing and comparing microbial communities. Appl. Environ. Microbiol. 75 (23), 7537-7541.

Shigematsu, T., Tang, Y., Mizuno, Y., Kawaguchi, H., Morimura, S., Kida, K., 2006. Microbial diversity of mesophilic methanogenic consortium that can degrade long-chain fatty acids in chemostat cultivation. J. Biosci. Bioeng. 102 (6), 535-544.

Sofer, S.S., Zaborsky, O.R., 1981. Biomass Conversion Processes for Energy and Fuels. Springer, US.

Sumino, H., Murota, R., Miyashita, A., Imachi, H., Ohashi, A., Harada, H., Syutsubo, K., 2012. Treatment of low-strength wastewater in an anaerobic down-flow hanging sponge (AnDHS) reactor at low temperature. J. Environ. Sci. Health Part a-Toxic/Hazardous Subst. Environ. Eng. 47 (12), 1803-1808.

US. EPA, 1993. Federal Register. Standards for Use or Disposal of Sewage Sludge. Final Rules. 40CFR, Part 503.

Vanlier, J.B., Hulsbeek, J., Stams, A.J.M., Lettinga, G., 1993. Temperature susceptibility of thermophilic methanogenic sludge: Implications for reactor start-up and operation. Bioresour. Technol. 43 (3), 227-235.

Wang, Q., Garrity, G.M., Tiedje, J.M., Cole, J.R., 2007. Naive Bayesian classifier for rapid assignment of rRNA sequences into the new bacterial taxonomy. Appl. Environ. Microbiol. 73 (16), 5261-5267.

Watanabe, H., Kitamura, T., Ochi, S., Ozaki, M., 1997. Inactivation of pathogenic bacteria under mesophilic and thermophilic conditions. Water Sci. Technol. 36 (6-7), 25-32.

Wei, F.S., 2002. Monitoring and Analysis Methods of Water and Wastewater, fourth ed. Chinese Environmental Sciences Publishment, China.

Weiss, A., Jerome, V., Freitag, R., Mayer, H.K., 2008. Diversity of the resident microbiota in a thermophilic municipal biogas plant. Appl. Microbiol. Biotechnol. 81 (1), 163-173.

Werner, J.J., Knights, D., Garcia, M.L., Scalfone, N.B., Smith, S., Yarasheski, K., Cummings, T.A., Beers, A.R., Knight, R., Angenent, L.T., 2011. Bacterial community structures are unique and resilient in full-scale bioenergy systems. Proc. Natl. Acad. Sci. U. S. A. 108 (10), 4158-4163.

Wu, S., Wang, G., Angert, E.R., Wang, W., Li, W., Zou, H., 2012. Composition, diversity, and origin of the bacterial community in grass carp intestine. Plos One 7 (2), e30440. 
Yabu, H., Sakai, C., Fujiwara, T., Nishio, N., Nakashimada, Y., 2011. Thermophilic two-stage dry anaerobic digestion of model garbage with ammonia stripping. J. Biosci. Bioeng. 111 (3), 312-319.

Zabranska, J., Dohanyos, M., Jenicek, P., Zaplatilkova, P., Kutil, J., 2002. The contribution of thermophilic anaerobic digestion to the stable operation of wastewater sludge treatment. Water Sci. Technol. 46 (4-5), 447-453.

Zhang, D., Zhu, W., Tang, C., Suo, Y., Gao, L., Yuan, X., Wang, X., Cui, Z., 2012. Bioreactor performance and methanogenic population dynamics in a low-temperature $\left(5-18^{\circ} \mathrm{C}\right)$ anaerobic fixed-bed reactor. Bioresour. Technol. 104, 136-143. Zinder, S.H., Cardwell, S.C., Anguish, T., Lee, M., Koch, M., 1984. Methanogenesis in a thermophilic $\left(58^{\circ} \mathrm{C}\right)$ anaerobic digestor: Methanothrix sp. as an important aceticlastic methanogen. Appl. Environ. Microbiol. 47 (4), 796-807.

Zinder, S.H., Mah, R.A., 1979. Isolation and characterization of a thermophilic strain of Methanosarcina unable to use $\mathrm{H}_{2}-\mathrm{CO}_{2}$ for methanogenesis. Appl. Environ. Microbiol. 38 (5), 996-1008. 